\section{Firmanto Latief}

Magister IImu Pemerintahan Universitas

Muhammadiyah Yogyakarta

Email: firmanto.latief@yahoo.com

\section{Dyah Mutiarin}

Dosen Magister IImu Pemerintahan

Muhammadiyah Yogyakarta

Email: mutiarin@yahoo.com
Transparansi Pengelolaan Anggaran

$$
\text { Daerah Di Satuan Kerja Perangkat }
$$

Daerah (SKPD) Kabupaten Bulukumba

http://dx.doi.org/10.18196/jgpp.2016.0058

\begin{abstract}
The problems discussed in this study is the transparency of budget management in the area work unit (SKPD) Bulukumba Lodging at the Department of Education, Youth and Sports Bulukumba, Department of Health, Office of Financial Management and the Department of Highways. This study aims to determine the performance of transparency in the management of local budgets in the regional work units Bulukumba and factors that affect the application of transparency. The method used in this penelitiian is the combination of qualitative and quantitative methods, sample in this study of 60 people with menggunanakan purposive sampling method. There are two types of data analysis applied in this study, the analysis of qualitative and quantitative analysis. The results showed that the transparency of budget management conducted by the Department of Education, Youth and Sports Bulukumba of several indicators has a value of cumulative index 2:02 by category Less Good, transparency of budget management conducted by the Office of Financial Management Bulukumba of several indicators has a value of cumulative index 2. 81 with good category, transparency of budget management is conducted by the Department of Health Bulukumba of several indicators has a cumulative index score of 1.98 with the category of Less Good, transparency of budget management is carried out by the Highways Agency Bulukumba of several indicators has a cumulative index score 2:09 with Less Good category.

Keyword: Transparency, Local Budget Management
\end{abstract}

\title{
ABSTRAK
}

Permasalahan yang dibahas dalam penelitian ini adalah transparansi pengelolaan anggaran daerah di satuan kerja perangkat daerah (SKPD) Kabupaten Bulukumba Khusus pada Dinas Pendidikan, Pemuda dan Olahraga Kabupaten Bulukumba, Dinas Kesehatan, Dinas Pengelolaan Keuangan Daerah dan Dinas Bina Marga. Penelitian ini bertujuan untuk mengetahui kinerja transparansi dalam pengelolaan anggaran daerah di Satuan Kerja Perangkat Daerah Kabupaten Bulukumba dan faktor yang mempengaruhi penerapan transparansi. Metode yang digunakan dalam penelitiian ini adalah penggabungan antara metode kualitatif dan kuantitatif, Sampel dalam penelitian ini sebanyak 60 orang dengan menggunanakan metode purposive sampling. Terdapat dua jenis analisis data yang diterapkan dalam penelitian ini, yaitu analisis kualitatif dan analisis kuantitatif. Hasil penelitian menunjukkan bahwa transparansi pengelolaan anggaran yang dilakukan oleh Dinas Pendidikan, Pemuda dan Olahraga Kabupaten Bulukumba dari beberapa indikator memiliki nilai indeks kumulatif 2. 02 dengan kategori Kurang Baik, Transparansi pengelolaan anggaran yang dilakukan oleh Dinas Pengelolaan Keuangan Daerah Kabupaten Bulukumba dari beberapa indikator memiliki nilai indeks kumulatif 2. 81 dengan kategori Baik, Transparansi pengelolaan anggaran yang dilakukan oleh Dinas Kesehatan Kabupaten Bulukumba dari beberapa indikator memiliki nilai indeks kumulatif 1, 98 dengan kategori Kurang Baik, Transparansi pengelolaan anggaran yang dilakukan oleh Dinas Bina Marga Kabupaten Bulukumba dari beberapa indikator memiliki nilai indeks kumulatif 2. 09 dengan kategori Kurang Baik.

Kata Kunci : Transparansi, Pengelolaan Anggaran Daerah 


\section{PENDAHULUAN}

Keinginan untuk mewujudkan good governance merupakan salah satu agenda pokok reformasi yang diharapkan dapat dilaksanakan secara konsisten oleh pemerintah daerah. Masyarakat menuntut adanya akuntabilitas yang baik disertai dengan transparansi dan keterbukaan pengelolaan anggaran supaya masyarakat dapat turut serta dalam mengontrol dan memperbaiki kinerja pemerintah daerah. Menjawab tuntutan masyarakat dalam rangka mewujudkan good governance tersebut dalam kaitannya dengan pelaksanaan otonomi daerah, maka diperlukan reformasi pengelolaan keuangan daerah dan reformasi keuangan negara. Penerapan otonomi daerah seutuhnya membawa konsekuensi logis berupa penyelenggaraan pemerintahan dan pembangunan berdasarkan manajemen keuangan yang sehat. Dalam hal ini pemerintah telah mengeluarkan serangkaian kebijakan manajemen keuangan daerah, antara lain UndangUndang No. 25 Tahun 1999 tentang Perimbangan Keuangan antara Pemerintah Pusat dan Daerah, Undang-undang Nomor 17 Tahun 2003 tentang Keuangan Negara, Undang-Undang Nomor 33 Tahun 2004 tentang Perimbangan Keuangan antara Pemerintah Pusat dan Pemerintah Daerah, Peraturan Pemerintah Nomor 58 Tahun 2005 tentang Pengelolaan Keuangan Daerah dan Undang-undang No. 14 tahun 2008 tentang keterbukaan informasi, dalam undang-undang tersebut sangat jelas di sebutkan bahwa setiap Organisasi, Badan atau Lembaga Publik yang sebagian atau seluruh dananya bersumber dari APBN atau APBD harus menggunakan sistem informasi yang terbuka. Terbuka dalam artian bahwa setiap orang mudah dan berhak untuk mengaksesnya. Tujuan penerapan prinsip transparansi pengelolaan anggaran daerah di satuan kerja perangkat daerah (SKPD) yaitu agar tidak terjadi lagi tindak pidana korupsi seperti kasus yang terjadi di berbagai wilayah di Indonesia misalnya kasus korupsi 
pembangunan Rumah Sakit Umum Daeah (RSUD) Ponorogo Jawa Timur yang menelan anggaran multi years senilai Rp 156 miliar $^{1}$. Kasus korupsi di instansi Badan Penaggulangan Bencana Daerah (BPBD) atas korupsi pengadaan mobil pemadam kebakaran (Damkar) yang mengunakan dana APBD Tahun Anggaran 2014 sebesar Rp. 1. 403. 545. 000, -2. Khusus di Kabupaten Bulukumba yaitu kasus pengadaan perangkat teknologi, informasi, dan komunikasi (TIK) di Dinas Pendidikan, Pemuda, dan Olahraga Bulukumba dimana Kepolisian Resort Bulukumba menetapkan Bendahara Partai Golkar Bulukumba, Arifuddin, sebagai tersangka. Selain Arifuddin, penyidik juga memeriksa Kepala Rumah Sakit Umum Sultan Daeng Raja Bulukumba dr Diyah Marni. diperiksa terkait dugaan penyalahgunaan anggaran jasa dokter dan pelayanan kesehatan di Rumah Sakit Sultan Daeng Raja, Bulukumba, Tahun Anggaran (TA) 2009 sebesar Rp4, 6 miliar³.

Dengan melihat berbagai kasus tersebut diatas, maka penulis tertarik menulis tentang "Transparansi Pengelolaan Anggaran Daerah di Satuan Kerja Perangkat Daerah (SKPD) Kabupaten Bulukumba” dengan rumusan masalah bagaimana kinerja transparansi dalam pengelolaan anggaran daerah di Satuan Kerja Perangkat Daerah Kabupaten Bulukumba?

\section{KARANGKA TEORI}

\section{Good Governance}

Budi Wiyoto (2005) mengatakan arti good dan good governance mengandung dua pengertian, yaitu : pertama, mengandung makna tentang orientasi ideal negara yang diarahkan pada pencapaian tujuan negara. Berorientasi pada nilai yang menjunjung tinggi kehendak rakyat dalam mencapai kemandirian, pembangunan berkelanjutan, keadilan sosial,

1 TRIBUNnews. com, Minggu 28 Desember 2014

2 Sumsel. com, senin, 20 April 2015

${ }^{3}$ Tempo. com. Jum'at, 27 Desember 2013 
demokratisasi dalam kehidupan bernegaran seperti legimitasi, akuntabilitas, perlindungan HAM, otonomi dan pemberdayaan masyarakat. Kedua, mengandung makna tentang aspek-aspek fungsional pemerintahan yang efektif dan efesien, atau pemerintah yang bersifat ideal, yaitu mampu berfungsi secara efektif dalam upaya mencapai tujuan nasional ${ }^{4}$.

\section{Transparansi}

Transparansi yang dimaksud dalam penelitian ini adalah terbukanya akses bagi masyarakat dalam memperoleh informasi mengenai perencanaan, pelaksanaan, pengawasan dan tanggungjawab Anggaran daerah yang di kelola oleh Satuan Kerja Perangkat Daerah (SKPD). Hal ini di dasarkan pada pendapat beberapa ahli, yaitu sebagai berikut:

Hamid Muhammad (2007) Transparansi adalah keterbukaan atas semua tindakan dan kebijakan yang diambil oleh pemerintah Prinsip transparansi menciptakan kepercayaan timbal-balik antara pemerintah dan masyarakat melalui penyediaan informasi dan menjamin kemudahan di dalam memperoleh informasi yang akurat dan memadai ${ }^{5}$. Menurut Logos (2005) transparansi dan akuntabilitas merupakan konsep yang berkaitan erat satu dengan yang lain, karena tanpa transparansi tidak mungkin ada akuntabilitas. Sebaliknya transparansi tidak akan banyak bermanfaat tanpa dilengkapi dengan akuntabilitas ${ }^{6}$.

Mardiasmo (2002) menyebutkan transparansi adalah keterbukaan pemerintah dalam memberikan informasi yang terkait dengan aktifitas pengelolaan sumber daya publik kepada pihak yang membutuhkan yaitu

4 Budi Wiyoto , 2002, Teori dan Proses Kebijakan Publik, Media Pressindo Yogyakarta. Hal:18

\footnotetext{
${ }^{5}$ Hamid Muhammad , 2003, Akuntansi Pemerintahan, Jakarta, lembaga penerbit fakultas Ekonomi Universitas Indonesia. Hal : 31

6 Logos. 2005 Transparansi, Akuntabilitas, dan Kontrol Dalam Pembiayaan Pertahanan (Problem dan Rekomendasi). Hal : 24
} 
masyarakat. Mardiasmo menyebutkan tujuan transparansi dalam penyelenggaraan pemerintahan yaitu :

1. Salah satu wujud pertanggungjawaban pemerintah kepada masyarakat

2. Upaya peningkatan manajemen pengelolaan pemerintahan

3. Upaya peningkatan manajemen pengelolaan dan penyelenggaraan pemerintahan yang baik dan mengurangi kesempatan praktek $\mathrm{KKN}^{7}$.

\section{Pengelolaan Keuangan Daerah}

Menurut Tjahjanulin (2002) pengelolaan keuagan adalah proses pengurusan, penyelengaraan, penyediaan, dan penggunaan uang dalam setiap usaha kerjasama sekelompok orang untuk tercapai suatu tujuan. Proses ini tersusun dari pelaksanaan fungsi-fungsi penganggaran pembukuan dan pemeriksaan atau secara operasioal apabila dirangkaikan dengan daerah maka pengelolaan keuangan daerah adalah pelaksanaan meliputi penyusunan, penetapan, pelaksanaan pengawasan dan perhitungan anggaran pendapan dan belanja daerah (APBD) ${ }^{8}$.

Menurut Abdul Halim (2004) mengatakan, membicarakan pengelolaan keuangan daerah tidak terlepas dari pembahasan anggaran pendapatan dan belanja daerah. Oleh karena itu, anggaran pendapatan dan belanja daerah adalah merupakan suatu program kerja suatu daerah dalam bentuk angkaangka selama satu tahun anggaran ${ }^{9}$.

\footnotetext{
${ }^{7}$ Mardiasmo. 2002. Otonomi dan Manajemen Keuangan Daerah. Yogyakarta: Andi.

8 Tjahjanulin, Domai. 2002. "Buku Ajar Administrasi Keuangan Daerah". Fakultas IImu Administrasi Universitas Brawijaya. Hal : 52

9 Halim, Abdul. 2004. Manajemen Keuangan Daerah. UPP AMP YKPN, Yogyakarta. Hal : 53
} 


\section{Kerangka Pikir Penelitian}

Transparansi adalah prinsip yang menjamin akses atau kebebasan bagi setiap orang untuk memperoleh informasi tentang penyelenggaraan pemerintahan, yakni informasi tentang kebijakan, proses pembuatan dan pelaksanaannya, serta hasil-hasil yang dicapai. Secara garis besar bahwa transparansi sangat dibutuhkan dalam pengelolaan anggaran daerah yang meliputi perencanaan, pelaksanaaan, pengawasan serta pertanggungjawaban mengenai pengelolaan keuangan daerah pada Satuan Kerja Perangkat Daerah (SKPD) dimana dengan adanya transparansi keuangan maka akan meminimalkan munculnya keragu-raguan akan kinerja para pegawai dalam hal mengelola keuangan dan tidak terjadi lagi tindak pidana korupsi.

\section{Bagan Karangka Pikir}

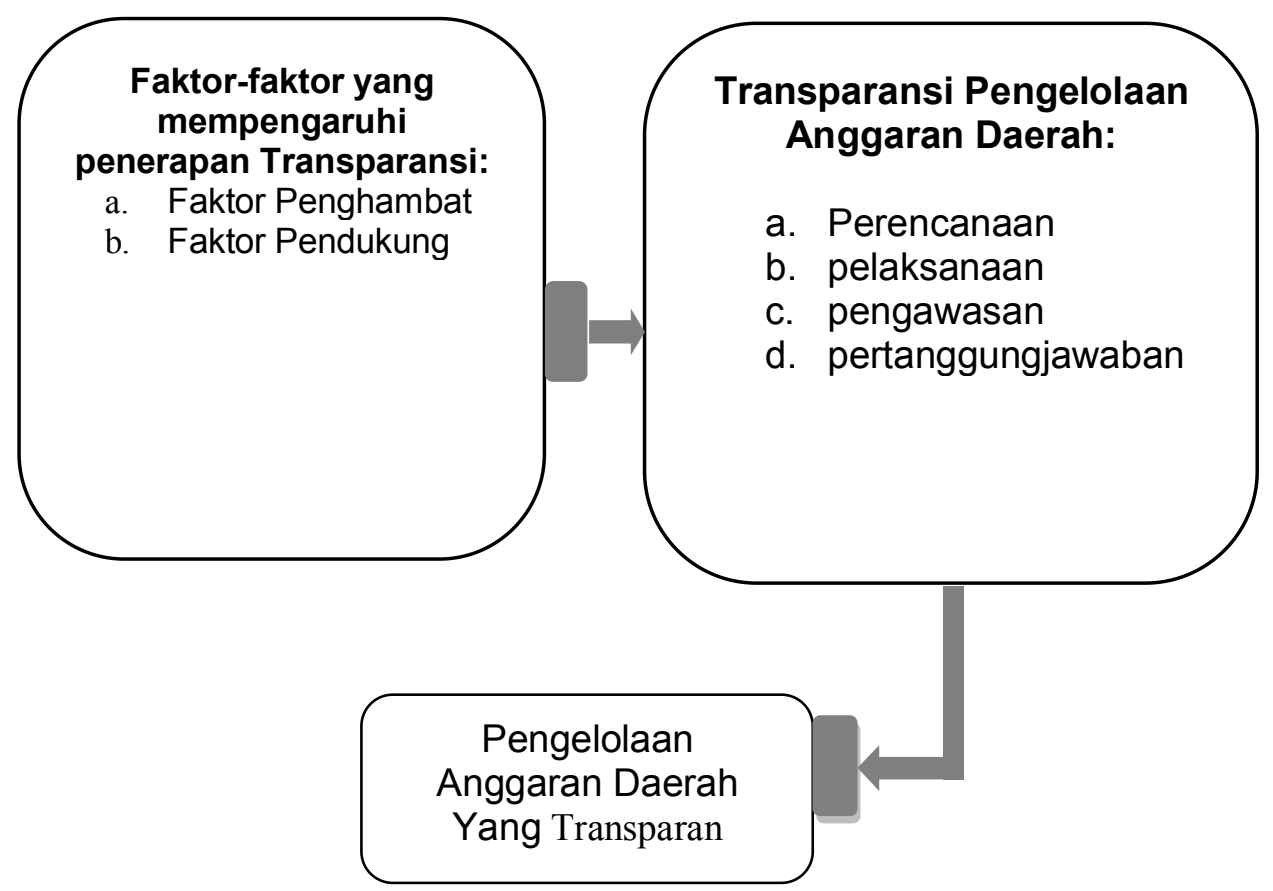

Sumber : Penulis 2015 


\section{Definisi Operasional}

Definisi operasional merupakan definisi yang menyatakan seperangkat petunjuk atau operasi yang lengkap tentang apa yang harus diamati dan bagaimana mengamatinya. Sehingga Definisi operasional dalam penelitian ini adalah transparansi pengelolaan keuangan daerah yang terdiri dari perencanaan, pelaksanaan, pengawasan serta pertanggungjawaban mengenai Pengelolaan Keuangan Daerah.

Dimensi dan indikator dalam transparansi pengelolaan keuangan daerah dapat dilihat pada tabel dibawah ini:

Tabel 1

Definisi Operasional

\begin{tabular}{|c|c|c|c|}
\hline No & Variabel & Dimensi & Indikator \\
\hline \multirow{4}{*}{1} & \multirow{4}{*}{$\begin{array}{l}\text { Transpara } \\
\text { nsi } \\
\text { Pengelola } \\
\text { an } \\
\text { Keuangan } \\
\text { Daerah }\end{array}$} & Perencanaan & $\begin{array}{l}\text { 1. Terdapat pengumuman kebijakan } \\
\text { mengenai pengelolaan keuangan } \\
\text { daerah. } \\
\text { 2. Keterbukaaan dalam rapat penting } \\
\text { dimana masyarakat ikut } \\
\text { memberikan pendapatnya. }\end{array}$ \\
\hline & & Pelaksanaan & $\begin{array}{l}\text { 1. Terdapat sistem pemberian } \\
\text { informasi kepada publik yang siap, } \\
\text { mudah dijangkau, bebas diperoleh, } \\
\text { dan terkini yang perlu diketahui } \\
\text { oleh masyarakat. } \\
\text { 2. Keterbukaan Informasi Adanya } \\
\text { sanksi yang ditetapkan atas } \\
\text { kesalahan atau kelalaian dalam } \\
\text { pelaksanaan. }\end{array}$ \\
\hline & & Pengawasan & $\begin{array}{l}\text { 1. Meningkatkan arus informasi } \\
\text { melalui kerjasama dengan media } \\
\text { massa dan lembaga non } \\
\text { pemerintahan. }\end{array}$ \\
\hline & & $\begin{array}{c}\text { Pertanggungj } \\
\text { awaban }\end{array}$ & $\begin{array}{l}\text { 1. } \begin{array}{l}\text { Tersedia laporan } \\
\text { pertanggungjawaban yang tepat } \\
\text { waktu. }\end{array}\end{array}$ \\
\hline
\end{tabular}

Sumber: Penulis 2015 


\section{METODE PENELITIAN}

Penelitian ini menggunakan metode penelitian kuantitatif melalui statistik deskriptif dan desktiptif kualitatif untuk mengkaji tentang transparansi pengelolaan anggaran daerah di satuan kerja perangkat daerah (SKPD) Kabupaten Bulukumba. Penelitian ini berlokasi di Satuan Kerja Perangkat Daerah kabupaten Bulukumba yaitu di Dinas Pendidikan, Pemuda dan Olahraga Kabupaten Bulukumba, Dinas Pengelolaan Keuangan Daerah, Dinas Kesehatan, dan Dinas Bina Marga dengan alasan dan pertimbangan bahwa SKPD yang 4 tersebut diatas adalah penggunan anggaran tertinggi ditahun 2014 sehingga perlu mendapatkan perhatian yang lebih dari semua kalangan yang terkait. Jenis data yang digunakan adalah data primer dan sekunder. Teknik pengumpulan data dengan melakukan wawancara untuk mengungkapkan data dan informasi dari sumber langsung yang sifat datanya berhubungan dengan makna-makna yang berada dibalik perilaku dan situasi sosial yang terjadi, dokumentasi, kuesioner. unit analisisnya adalah pengguna eksternal pengelolaan anggaran pemerintah daerah kabupaten Bulukumba, yaitu pegawai Dinas Pendidikan, Pemuda dan Olahraga Kabupaten Bulukumba, Dinas Pengelolaan Keuangan Daerah, Dinas Kesehatan, Dinas Bina Marga, Badan Pengawas Daerah (Bawasda), dan Masyarakat. Sampel dalam penelitian ini sebanyak 60 orang dengan menggunanakan metode purposive sampling dan jenis analisis data yang diterapkan dalam penelitian ini, yaitu analisis kualitatif dan analisis kuantitatif. Analisis kualitatif digunakan untuk menganalisis hasil wawancara, dokumentasi dan data-data deskriptif lainnya. Data yang telah dikumpulkan akan dianalisis dengan pendekatan model interaktif sebagaimana diajukan oleh Miles dan Huberman dalam Sugiyono (2014), yaitu terdiri dari reduksi data, penyajian data, dan penarikan kesimpulan/verifikasi serta analisis kuantitatif digunakan untuk menganalisis hasil kuesioner menganai 
penerapan prinsip transparansi di Dinas Pendidikan, Pemuda dan Olahraga Kabupaten Bulukumba, Dinas Pengelolaan Keuangan Daerah, Dinas Kesehatan, dan Dinas Bina Marga ${ }^{10}$.

\section{DESKRIPSI WILAYAH PENELITIAN}

Kabupaten Bulukumba terletak dibagian selatan dari jazirah Sulawesi Selatan dan berjarak $153 \mathrm{~km}$ dari Makassar (Ibukota Propinsi Sulawesi Selatan). Luas wilayah Kabupaten Bulukumba 1. 154, $67 \mathrm{~km}^{2}$ atau 1, $85 \%$ dari luas wilayah Propinsi Sulawesi Selatan. Kabupaten Bulukumba terdiri dari 10 kecamatan yaitu Kecamatan Ujungbulu (Ibukota Kabupaten), Kecamatan Gantarang, Kecamatan Kindang, Kecamatan Rilau Ale, Kecamatan Bulukumpa, Kecamatan Ujungloe, Kecamatan Bontobahari, Kecamatan Bontotiro, Kecamatan Kajang dan Kecamatan Herlang. 3 kecamatan sentra pengembangan pertanian dan perkebunan yaitu Kecamatan Kindang, Kecamatan Rilau Ale dan Kecamatan Bulukumpa.

Secara geografis Kabupaten Bulukumba terletak pada koordinat antara $5^{\circ} 20^{\prime \prime}$ sampai $5^{\circ} 40^{\prime \prime}$ Lintang Selatan dan $119^{\circ} 50^{\prime \prime}$ sampai $120^{\circ} 28^{\prime \prime}$ Bujur Timur. Batas-batas wilayahnya adalah:

- Sebelah Utara: Kabupaten Sinjai

- Sebelah Selatan: Laut Flores

- Sebelah Timur: Teluk Bone

- Sebelah Barat: Kabupaten Bantaeng

10 Sugiyono, 2014. Metode penelitian kuantitatif, kualitatif dan R\&D. Alfabeta Bandung. Hal : 32 


\section{HASIL DAN PEMBAHASAN}

Pada bagian ini menejelaskan tentang hasil temuan dan analisis untuk menjawab rumusan masalah pada bagian pertama tentang bagaimana kinerja transparansi dalam pengelolaan anggaran daerah di Satuan Kerja Perangkat Daerah Kabupaten Bulukumba khususnya pada dinas pendidikan, dinas pengelolaan keuangan daerah, dinas kesehatan, dan dinas bina marga.

\section{Dinas Pendidikan, Pemuda dan Olahraga}

Transparansi pengelolaan anggaran daerah di dinas pendidikan, pemuda dan olahraga dari beberapa indikator dapat dilihat sebagai berikut:

Tabel 2

Indeks Parameter Transparansi Pengelolaan Anggaran Daerah Pada Dinas Pendidikan, Pemuda dan Olahraga Kabupaten Bulukumba

\begin{tabular}{|c|c|c|c|c|c|c|c|}
\hline \multicolumn{8}{|c|}{ Transparansi Pengelolaan Anggaran Daerah } \\
\hline \multirow{2}{*}{$\begin{array}{c}\text { INDIKA } \\
\text { TOR }\end{array}$} & SL & SR & $\mathrm{K}$ & TP & \multirow{2}{*}{$\mathbf{N}$} & \multirow{2}{*}{\multicolumn{2}{|c|}{ INDEKS }} \\
\hline & 4 & 3 & 2 & 1 & & & \\
\hline 1 & 5 & 8 & 15 & 32 & 60 & 1,75 & Tidak baik \\
\hline 2 & 4 & 4 & 17 & 35 & 60 & 1,62 & Tidak baik \\
\hline 3 & 8 & 5 & 17 & 30 & 60 & 1,85 & Kurang baik \\
\hline 4 & 3 & 8 & 20 & 29 & 60 & 1,75 & Tidak baik \\
\hline 5 & 20 & 11 & 17 & 12 & 60 & 2,65 & Baik \\
\hline 6 & 15 & 14 & 20 & 11 & 60 & 2,55 & Kurang baik \\
\hline Total & 55 & 50 & 106 & 149 & & & \\
\hline \multicolumn{6}{|c|}{ Indeks Parameter } & \multicolumn{2}{|c|}{2,02} \\
\hline \multicolumn{6}{|c|}{ Kategori Nilai Indeks } & \multicolumn{2}{|c|}{ Kurang baik } \\
\hline
\end{tabular}

Sumber data: Hasil Olahan Data Kuesioner, 2015

Secara keseluruhan penulis menyimpulkan bahwa transparansi yang dilakukan oleh dinas pendidikan, pemuda dan olahraga dari beberapa indikator mulai dari perencanaan, pelaksanaan, pengawasan dan pertanggungjawaban masih perluh ditingkatkan karena dari hasil olahan data kuesiner seperti yang terlihat pada tabel 2 menunjukkan indeks parematernya berada pada angka 2, 02 yang berada pada kategori Kurang baik. ini diakibatkan karena tidak adanya inisiatif dari pimpinan atau atasan 
untuk serius mempublikasikan anggaran dan berdasarkan hasil wawacara yang dilakukan memang diakui oleh pimpinan dari dinas pendidikan bahwa sejauh ini belum ada tindakan untuk mempublikasikan anggaran yang dikelolanya karena menurutnya harus dilakukan bersama-sama mulai dari tingkat atas hingga pada truktur terbah di dinas kesehatan. maka yang harus dilakukan oleh dinas pendidikan yaitu lebih ditingkatkan lagi dalam hal transparansi anggaran daerah yang dikelolahnya agar kepercayaan masyarakat terhadap dinas pendidikan ini bisa meningkat dan dapat membantu pemerintah daerah dalam muwujudkan good governance.

\section{Dinas Pengelolaan Keuangan Daerah}

Transparansi pengelolaan anggaran daerah di dinas Pengelolaan Keuangan Daerah dari beberapa indikator dapat dilihat sebagai berikut:

Tabel 3

Indeks Parameter Transparansi Pengelolaan Anggaran Daerah Pada Dinas Pengelolaan Keuangan Daerah Kabupaten Bulukumba

\begin{tabular}{|c|c|c|c|c|c|c|c|}
\hline \multicolumn{8}{|c|}{ Transparansi Pengelolaan Anggaran Daerah } \\
\hline \multirow{2}{*}{$\begin{array}{c}\text { INDIKA } \\
\text { TOR }\end{array}$} & SL & SR & $\mathbf{K}$ & TP & \multirow{2}{*}{$\mathbf{N}$} & \multirow{2}{*}{\multicolumn{2}{|c|}{ INDEKS }} \\
\hline & 4 & 3 & 2 & 1 & & & \\
\hline 1 & 17 & 24 & 12 & 7 & 60 & 2,85 & Baik \\
\hline 2 & 14 & 13 & 19 & 14 & 60 & 2,48 & Kurang baik \\
\hline 3 & 24 & 16 & 11 & 9 & 60 & 2,95 & Baik \\
\hline 4 & 17 & 10 & 25 & 8 & 60 & 2,60 & Baik \\
\hline 5 & 27 & 10 & 16 & 7 & 60 & 2,95 & Baik \\
\hline 6 & 28 & 15 & 10 & 7 & 60 & 3,06 & Baik \\
\hline Total & 127 & 88 & 93 & 52 & & & \\
\hline \multicolumn{6}{|c|}{ Indeks Parameter } & \multicolumn{2}{|r|}{ 2. 81} \\
\hline \multicolumn{6}{|c|}{ Kategori Nilai Indeks } & \multicolumn{2}{|r|}{ Baik } \\
\hline
\end{tabular}

Sumber data: Hasil Olahan Data Kuesioner, 2015

Secara keseluruhan penulis menyimpulkan bahwa transparansi yang dilakukan oleh dinas pengelolaan keuangan daerah dari beberapa indikator mulai dari perencanaan, pelaksanaan, pengawasan dan pertanggungjawaban sudah cukup baik karena dari hasil olahaan data kuesiner seperti yang 
terlihat pada tabel 3 menunjukkan indeks parematernya berada pada angka
2, 81 yang berada pada kategori baik yang artinya dinas pengelolaan keuangan daerah sudah dilakukan dengan baik namun tidak bisa di pungkiri masih banyak lagi yang harus dibenahi dan ditingkatkan agar dapat lebih transparansi dan masyarakat Bulukumba juga makin percaya atas anggaran yang dikelolaah oleh dinas pengelolaan keuangan daerah kabupaten Bulukumba. Keberhasilan ini diakui kerna kerja sama di internal dinas pengelolaan keuangan dan inisitif dari pimpinan dan setiap staf yang ada di dinas pengelolaan untuk mempublikasikan anggaran yang di kelolanya dengan cara membuat papan informasi di halam kantor dan mejalin kerjasama dengan media local yang ada di kabupaten Bulukumba.

\section{Dinas Kesehatan}

Transparansi pengelolaan anggaran daerah di dinas kesehatan dari beberapa indikator dapat dilihat sebagai berikut:

Tabel 4

Indeks Parameter Transparansi Pengelolaan Anggaran Daerah Pada Dinas Kesehatan Daerah Kabupaten Bulukumba

\begin{tabular}{|c|c|c|c|c|c|c|c|}
\hline \multicolumn{8}{|c|}{ Transparansi Pengelolaan Anggaran Daerah } \\
\hline \multirow{2}{*}{$\begin{array}{c}\text { INDIKA } \\
\text { TOR }\end{array}$} & SL & SR & $\mathbf{K}$ & TP & \multirow{2}{*}{$\mathbf{N}$} & \multirow{2}{*}{\multicolumn{2}{|c|}{ INDEKS }} \\
\hline & 4 & 3 & 2 & 1 & & & \\
\hline 1 & 11 & 8 & 12 & 29 & 60 & 2,01 & Kurang baik \\
\hline 2 & 6 & 9 & 17 & 28 & 60 & 1,88 & Kurang baik \\
\hline 3 & 9 & 10 & 18 & 23 & 60 & 2,08 & Kurang baik \\
\hline 4 & 9 & 7 & 18 & 26 & 60 & 1,98 & Kurang baik \\
\hline 5 & 9 & 12 & 26 & 13 & 60 & 2,28 & Kurang baik \\
\hline 6 & 7 & 8 & 15 & 30 & 60 & 1,70 & Tidak baik \\
\hline Total & 51 & 49 & 106 & 149 & & & \\
\hline \multicolumn{6}{|c|}{ Indeks Parameter } & \multicolumn{2}{|c|}{1,98} \\
\hline \multicolumn{6}{|c|}{ Kategori Nilai Indeks } & \multicolumn{2}{|c|}{ Kurang baik } \\
\hline
\end{tabular}

Sumber data: Hasil Olahan Data Kuesioner , 2015

Secara keseluruhan penulis menyimpulkan bahwa transparansi yang dilakukan oleh dinas kesehatan dari beberapa indikator mulai dari perencanaan, pelaksanaan, pengawasan dan pertanggungjawaban harus 
ditingkatkan lagi karena dari hasil olahaan data kuesiner seperti yang terlihat pada tabel 4 menunjukkan indeks parematernya berada pada angka 1, 98 yang berada pada kategori Kurang baik, ini diakibatkan karena masih sulitnya masyarakat untuk mengakses beberapa dokumen-dokumen yang berhubungan dengan anggaran daerah dimana ini artinya dinas kesehatan harus lebih ditingkatkan lagi dari beberapa indikator transparansi agar masyarakat bulukumba lebih percaya terhadap dinas kesehatan dalam mengelolaa anggaran daerah dan juga membantu pemerintah daerah dalam menerapkan Good Governance.

\section{Dinas Bina Marga}

Transparansi pengelolaan anggaran daerah di dinas kesehatan dari beberapa indikator dapat dilihat sebagai berikut:

Tabel 5

Indeks Parameter Transparansi Pengelolaan Anggaran Daerah Pada Dinas Bina Marga Kabupaten Bulukumba

\begin{tabular}{|c|c|c|c|c|c|c|c|}
\hline \multicolumn{8}{|c|}{ Transparansi Pengelolaan Anggaran Daerah } \\
\hline \multirow{2}{*}{$\begin{array}{l}\text { INDIKA } \\
\text { TOR }\end{array}$} & $\begin{array}{l}S \\
L\end{array}$ & SR & K & TP & \multirow[t]{2}{*}{$\mathbf{N}$} & \multirow{2}{*}{\multicolumn{2}{|c|}{ INDEKS }} \\
\hline & 4 & 3 & 2 & 1 & & & \\
\hline 1 & 9 & 13 & 20 & 18 & 60 & 2,21 & Kurang baik \\
\hline 2 & 5 & 20 & 18 & 17 & 60 & 2,21 & Kurang baik \\
\hline 3 & 8 & 10 & 25 & 17 & 60 & 2,15 & Kurang baik \\
\hline 4 & 7 & 8 & 19 & 26 & 60 & 1,93 & Kurang baik \\
\hline 5 & 7 & 13 & 24 & 16 & 60 & 2,18 & Kurang baik \\
\hline 6 & 6 & 11 & 15 & 28 & 60 & 1,91 & Kurang baik \\
\hline Total & $\begin{array}{l}4 \\
2\end{array}$ & 75 & 121 & 122 & & & \\
\hline \multicolumn{6}{|c|}{ Indeks Parameter } & \multirow{2}{*}{\multicolumn{2}{|c|}{$\frac{2,09}{\text { rang baik }}$}} \\
\hline & & ateg & ai In & & & & \\
\hline
\end{tabular}

Sumber data: Hasil Olahan Data Kuesioner, 2015

Secara keseluruhan penulis menyimpulkan bahwa transparansi yang dilakukan oleh dinas bina marga dari beberapa indikator mulai dari perencanaan, pelaksanaan, pengawasan dan pertanggungjawaban harus 
ditingkatkan lagi karena dari hasil olahaan data kuesiner seperti yang terlihat pada tabel 5 menunjukkan indeks parematernya berada pada angka 2, 09 yang berada pada kategori Kurang baik yang artinya dinas bina marga harus lebih memperbaiki lagi kinerjanya dalam pengelolaan anggaran daerah dimana hasil wawancara yang dilakukan memang dinas bina marga ini adalah salah satu dinas yang sering telat dalam pelaporan keuangan yang dikelolanya sehingga masyarakat bulukumba akan menaruh kecurigaan dalam pengelolaan anggaran yang dilakukan oleh dinas bina marga di tahuntahun berikutnya.

Tabel 6

Transparansi Pengelolaan Anggaran Daerah di Satuan Kerja Perangkat Daerah (SKPD) Kabupaten Bulukumba

\begin{tabular}{|c|c|c|c|c|c|c|c|c|}
\hline \multirow{3}{*}{ SKPD } & \multicolumn{6}{|c|}{ INDIKATOR TRANSPARANSI } & \multirow{3}{*}{$\begin{array}{l}\text { Rata- } \\
\text { Rata }\end{array}$} & \multirow{3}{*}{ Kategori } \\
\hline & \multicolumn{2}{|c|}{$\begin{array}{c}\text { Perencanaa } \\
\mathbf{n}\end{array}$} & \multicolumn{2}{|c|}{ Pelaksanaan } & \multirow{2}{*}{ 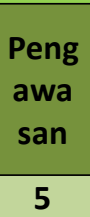 } & \multirow{2}{*}{$\begin{array}{c}\text { Pertan } \\
\text { ggung- } \\
\text { jawaba } \\
n \\
6\end{array}$} & & \\
\hline & 1 & 2 & 3 & 4 & & & & \\
\hline $\begin{array}{c}\text { Dinas } \\
\text { Pendidikan }\end{array}$ & 1,76 & $\begin{array}{l}1, \\
61\end{array}$ & 1,85 & 1,75 & 2,65 & 2,55 & 2,02 & $\begin{array}{c}\text { Kurang } \\
\text { baik }\end{array}$ \\
\hline $\begin{array}{c}\text { Dinas } \\
\text { Pengelolaan } \\
\text { Keuangan } \\
\text { Daerah }\end{array}$ & 2,45 & $\begin{array}{l}2 \\
45\end{array}$ & 3,1 & 2,6 & 2,95 & 3,06 & 2,81 & Baik \\
\hline $\begin{array}{c}\text { Dinas } \\
\text { Kesehatan }\end{array}$ & 2,01 & $\begin{array}{l}1, \\
88\end{array}$ & 2,08 & 1,98 & 2,28 & 1,70 & 1,98 & $\begin{array}{c}\text { Kurang } \\
\text { baik }\end{array}$ \\
\hline $\begin{array}{c}\text { Dinas Bina } \\
\text { Marga }\end{array}$ & 2,21 & $\begin{array}{l}2, \\
21\end{array}$ & 2,15 & 1,93 & 2,18 & 1,91 & 2,09 & $\begin{array}{c}\text { Kurang } \\
\text { baik }\end{array}$ \\
\hline Rata-rata & 2,1 & $\begin{array}{l}2, \\
03\end{array}$ & 2,29 & 2,06 & 2,51 & 2,30 & & \\
\hline
\end{tabular}

Dari tabel 6 diatas kita dapat melihat bahwa dinas pengelolaan keuangan daerahlah yang mendapatkan nilai rata-rata yang tertinggi dengan nilai indeksnya mencapai 2, 81 yang berapa pada kategori Baik, sedangkan dinas pendidikan, kesehatan dan bina marga masing-masing berapa pada 
kategori Kurang Baik. Ini menunjukkan bahwa diantara empat dinas yang penulis teliti ternyata dinas pengelolaan keuangan daerah yang sudah menerapakan prinsip transparansi dalam pengelolaan anggaran daerah dengan Baik dan dinas pengelolaan keuangan ini dapat menjadi contoh bagi dinas-dinas yang ada di kabupaten Bulukumba agar dapat mencapai indeks transparansi yang Baik bahkan dapat mencapai indeks sangat baik dalam pengelolaan anggaran daerah nantinya.

Tercapaiknya kategori Baik pada Dinas Pengelolaan Keuangan ini karena seorang sosok pemimpin yang berinisiatif untuk mempublikasikan setiap anggaran yang di kelolaanya dan ini juga di dukung dengan staf yang aktif memberikan informasi terhadap masyarakat dengan melakukan pelayanan terbaik disaat masyarakat membutuhkan informasi mengenai keuangan daerah atau pun hal-hal yang berkaitan dengan keuangan daerah serta keuntungan lainnya yang di dapat dalam penerapan prinsip transparansi anggaran daerah yaitu meningkatkan kepercayaan masyarakat terhadap aparat pemerintahan yang menjabat sekarang, tidak ada kecurigaan lagi antara masyarakat dan pemerintah, aparat yang menjabat dapat terhindar dari penyalagunaan jabatan atau wewenang dan pemerintah daerah dapat terhindar dari tindak pidana korupsi.

\section{KESIMPULAN DAN SARAN}

\section{Kesimpulan}

Berdasarkan hasil penelitian dan pembahasan yang telah diuraikan diatas, dapat ditarik sebuah kesimpulan mengenai transparansi pengelolaan anggaran daerah di SKPD Kabupaten Bulukumba tahun 2014 yaitu sebagai berikut:

Transparansi pengelolaan anggaran yang dilakukan oleh Dinas Pendidikan, Pemuda dan Olahraga Kabupaten Bulukumba dari beberapa indikator mulai dari proses perencanaan, pelaksanaan, pengawasan dan 
pertanggungjawaban memiliki nilai indeks kumulatif 2. 02 dengan kategori kurang baik dari nilai masksimal 4, 00 ini berarti masih perlu dan masih harus dibenahi lagi agar bisa mendapatkan nilai indeks kumulatif yang tinggi.

Transparansi pengelolaan anggaran yang dilakukan oleh Dinas Pengelolaan Keuangan Daerah Kabupaten Bulukumba dari beberapa indikator mulai dari proses perencanaan, pelaksanaan, pengawasan dan pertanggungjawaban memiliki nilai indeks kumulatif 2. 81 dengan kategori Baik dari nilai masksimal 4, 00 ini berarti dinas pengelolaan bisa menjadi contoh dari dinas lainya dalam hal transparansi penggelolaan anggaran daerah.

Transparansi pengelolaan anggaran yang dilakukan oleh Dinas Kesehatan Kabupaten Bulukumba dari beberapa indikator mulai dari proses perencanaan, pelaksanaan, pengawasan dan pertanggungjawaban memiliki nilai indeks kumulatif 1, 98 dengan kategori kurang baik dari nilai masksimal 4, 00 ini berarti masih perlu di benahi dari beberpa indikator transparansi agar bisa mendapatkan nilai indeks kumulatif yang tinggi.

Transparansi pengelolaan anggaran yang dilakukan oleh Dinas Bina Marga Kabupaten Bulukumba dari beberapa indikator mulai dari proses perencanaan, pelaksanaan, pengawasan dan pertanggungjawaban memiliki nilai indeks kumulatif 2. 09 dengan kategori kurang baik dari nilai masksimal 4, 00 ini berarti masih perluh di dibenahi lagi dari beberapa indikator penilaian transparansi pengelolaan anggaran daerah.

\section{Saran}

Dengan memperhatikan kesimpulan di atas dan menganalisa hasil pembahasan maka penulis merasa perlu memberikan masukan sebagai berikut :

Penerapan Transparansi Anggaran Daerah di Satuan Kerja Perangkat Daerah (SKPD) Kabupaten Bulukumba khususnya dinas pendidikan, dinas kesehatan dan dinas bina marga harus lebih di tingkatkan 
lagi karena hal ini menyangkut keterbukaan pemerintah dalam pemerintahan dan sudah sepatutnya SKPD di kabupaten Bulukumba menerapkan sikap transparan dalam menjalankan roda pemerintahan. Jika tidak, tentunya akan sangat banyak terjadi penyimpangan dan penyelewengan baik dalam pengambilan kebijakan maupun dalam penggunaan anggaran daerah.

Melakukan upaya-upaya lain untuk menunjang pelaksanaan transparansi agar tidak terlaksana secara manual saja yaitu dengan melakukan kerjasama dengan pihak media massa dan radio setempat serta pemanfaatan media informasi dan komunikasi lainnya untuk melakukan publikasi program kerja sehingga informasi dapat dijangkau secara luas oleh masyarakat. Memperkuat jaringan social dan diperlukan komitmen yang kuat dari seluruh stakeholder dalam hal pengelolaan keuangan yang transparan serta pemerintah kabupaten Bulukumba diharapkan dapat meningkatkan keberadaan jaringan-jaringan sosial yang berupa organisasiorganisasi kemasyarakatan.

Pemberian pendidikan nonformal kepada masyarakat sebagai upaya penguatan modal sosial dengan meningkatkan keterlibatan masyarakat dalam kegiatan, secara perlahan mengurangi peran fasilitator dalam pengambilan keputusan, serta meningkatkan intensitas kegiatan kepada masyarakat.

\section{DAFTAR PUSTAKA}

Budi Wiyoto , 2002, Teori dan Proses Kebijakan Publik, Media Pressindo Yogyakarta.

Hamid Muhammad, 2003, Akuntansi Pemerintahan, Jakarta, lembaga penerbit fakultas Ekonomi Universitas Indonesia.

Halim, Abdul. 2004. Manajemen Keuangan Daerah. UPP AMP YKPN, Yogyakarta.

Logos. 2005 Transparansi, Akuntabilitas, dan Kontrol Dalam Pembiayaan Pertahanan (Problem dan Rekomendasi).

Mardiasmo. 2002. Otonomi dan Manajemen Keuangan Daerah. Yogyakarta: Andi. 
23 Sugiyono, 2014. Metode penelitian kuantitatif, kualitatif dan R\&D. Alfabeta Bandung. Administrasi Universitas Brawijaya

Kusmayadi, 2005 "Upaya mewujudkan good government governance melalui pengelolaan keuangan daerah, dengan objek penelitian kabupaten-kabupaten Indonesia". Disertasi, tidak dipublikasi. Bandung: Program Pascasarjana-UNPAD.

Kurnia Sari Nur Pangesti, 2008, “Implementasi Sistem Akuntansi Keuangan SKPD: studi kasus Penerapan Permendagri Nomor 13 tahun 2006 di Pemerintah Daerah Kabupaten Batang", Disertasi, tidak dipublikasi. Bandung: Program Pascasarjana-UNPAD.

Mulyana, Budi, 2006, “ Pengaruh Penyajian Neraca Daerah dan Aksesibilitas Laporan Keuangan terhadap Transparansi dan Akuntabilitas Pengelolaan Keuangan Daerah", Jurnal Akuntansi Pemerintahan Vol. 2 No. 1, Mei 2006

Sumsel. com, senin, 20 April 2015

TRIBUNnews. com, Minggu 28 Desember 2014

Tempo. com. Jum'at, 27 Desember 2013 
